\title{
Inhibition of CK2 enhances UV-triggered apoptotic cell death in lung cancer cell lines
}

\author{
TIESUO ZHAO ${ }^{1 *}$, HUIJIE JIA ${ }^{2 *}$, LIFEI LI $^{3}$, GUOLIANG ZHANG $^{4}$, MIN ZHAO $^{1}$, \\ QIAN CHENG ${ }^{1}$, JUNNIAN ZHENG ${ }^{1}$ and $\mathrm{DI} \mathrm{LI}^{5}$ \\ ${ }^{1}$ Jiangsu Key Laboratory of Biological Cancer Therapy, Xuzhou Medical College, Xuzhou, Jiangsu 221002; \\ ${ }^{2}$ Laboratory of Transplantation and Immunology, Xuzhou Medical College, Xuzhou, Jiangsu 221000; \\ Departments of ${ }^{3}$ Respiration and ${ }^{4}$ Laboratory Medicine, Affiliated Hospital of Inner Mongolia University \\ for the Nationalities, Tongliao, Inner Mongolia 028007; ${ }^{5}$ Department of Anatomy, The Medical College \\ of Inner Mongolia University for the Nationalities, Tongliao, Inner Mongolia 028000, P.R. China
}

Received November 29, 2012; Accepted February 11, 2013

DOI: 10.3892/or.2013.2407

\begin{abstract}
Lung cancer is a high-grade malignancy with poor 5 year-survival rates that remains incurable with current therapies. Different cellular stresses, including antitumor agents, ionizing radiation and ultraviolet (UV) light, can induce apoptosis and activate signaling pathways. UV has multiple effects on tumor cells, including DNA damage, and increases the expression of some genes involved in tumor cell apoptosis and DNA repair. It has been reported that UV can also activate casein kinase 2 (CK2). CK2, a Ser/Thr protein kinase, has been reported to be frequently overexpressed in various types of human cancer, including lung cancer, and is associated with tumor development. Thus, combination of UV and CK2 inhibitors may be a new strategy for the treatment of lung cancer. Our results demonstrated that inhibition of $\mathrm{CK} 2 \mathrm{a}$ through CK2 siRNA or a CK2 inhibitor [(4,5,6,7-tetrabromobenzotriazole (TBB)] enhances the decrease in cell viability of lung cancer cells (A549 and H2030) induced by UV. Western blot analysis demonstrated that the combination increased the expression of apoptotic protein markers cytochrome $c$ and the cleavage of poly ADP-ribose polymerase (PARP) and caspase-3. Furthermore, our results indicated that UV decreased the expression of the tumor suppressor protein PML through activation of CK2. Inhibition of CK2 by CK2 siRNA and TBB can recover the reduction of PML induced by UV. Collectively, these results demonstrate the significant apoptosis of lung cancer cells induced by combination treatment of the CK2 inhibitor and UV radiation. CK2 enhanced cell apoptosis by UV radiation may due, at least partly, to recover
\end{abstract}

Correspondence to: Dr Di Li, Department of Anatomy, The Medical College of Inner Mongolia University for the Nationalities, Tongliao, Inner Mongolia 028000, P.R. China

E-mail: jichu888@163.com

*Contributed equally

Keywords: casein kinase 2 siRNA, 4,5,6,7-tetrabromobenzotriazole, ultraviolet, lung cancer cell, anticancer therapy the expression of PML. These findings warrant the clinical testing of CK2 inhibitors which, when used in conjunction with DNA-damaging agents such as radiation, may be an effective cancer therapeutic strategy.

\section{Introduction}

Lung cancer is the leading cause of cancer-related mortality in China and worldwide (1); it is a high-grade malignancy with a poor 5 year-survival rate that remains incurable with current therapies. The severity of the situation has led researchers to combinative therapeutic strategies. Deregulation of cell survival and resistance to apoptosis are regarded as crucial aspects of tumorigenesis. Several toxic DNA-damaging agents, such as ionizing radiation (2) and ultraviolet (UV) radiation (3-5), are associated with cell apoptosis and have been used for tumor radiation therapy.

The MAPK signal transduction pathway is mainly responsible for UV-induced cell apoptosis (6). The MAPK family consists of at least four families that include extracellular signal-regulated kinase (ERK), c-Jun NH2-terminal kinase (JNK), p38, and ERK5/BMK1. The MAPK family regulates a wide variety of cellular responses such as proliferation, differentiation and apoptosis, which could be activated by various extracellular signals including growth factors and cellular stress such as UV irradiation, protein synthesis inhibitors and hydrogen peroxide $(7,8)$. The p38 MAPK signal pathway has been shown to play a critical role in the UV relative apoptosis (9). In mammalian cells, p38 MAPK is strongly activated in response to stress stimuli ranging from osmotic shock to inflammatory cytokines to UV and ionizing radiation, resulting in CK2 activation $(10,11)$.

Several studies have demonstrated that CK2 kinase activity can be stimulated following UV radiation in a p38-dependent manner $(10,12)$. As one of the important substrates of p38, CK2 may be activated by p38 MAPK in response to stress, through a direct protein-protein interaction $(13,14)$. Significantly, casein kinase 2 (CK2) is frequently overexpressed in various types of human cancer, including lung cancer (15), and can cause mammary tumors (16-20) and lymphomas (21). Traditionally, 
CK2 has been accepted as a constitutively active, highly conserved and ubiquitous serine/threonine protein kinase in search of specific physiological functions (22). However, several studies have demonstrated that CK2 plays a key role in the regulation of cell proliferation and apoptosis $(23,24)$.

Based on these data, we inquired about the role of CK2 in apoptosis induced by UV. Therefore, in the present study, we inhibited the CK2 activation through CK2a siRNA and $\mathrm{CK} 2$ inhibitor TBB, together with UV radiation, to investigate whether the combination would enhance the cell apoptosis on two different human lung cancer cell lines, A549 and H2030, and we explored the possible underlying mechanism.

\section{Materials and methods}

Materials. CK2a siRNA plasmid was purchased from Santa Cruz Biotechnology, Inc. (Santa Cruz, CA, USA; sc-29918). 3-(4,5-dimethylthiazol-2-yl)-2,5-diphenyltetrazolium bromide (MTT) and 4,5,6,7-tetrabromobenzotriazole (TBB) were purchased from Sigma. Fetal bovine serum (FBS), Dulbecco's modified Eagle's medium (DMEM), penicillin and $100 \mathrm{mg} / \mathrm{ml}$ streptomycin were purchased from Gibco. The antibodies anticytochrome $c$, anti-caspase-3, anti-cleaved caspase-3, anti-poly ADP-ribose polymerase (PARP), anti-PML, anti-p38 and antip-p38 were purchased from Santa Cruz Biotechnology.

Cell culture. The human A549 and H2030 cells were cultured in DMEM with $10 \% \mathrm{FBS}, 100 \mathrm{U} / \mathrm{ml}$ penicillin, and $100 \mathrm{mg} / \mathrm{ml}$ streptomycin (Gibco) under standard culture conditions $\left(37^{\circ} \mathrm{C}\right.$ and $5 \% \mathrm{CO}_{2}$ ). The $\mathrm{A} 549$ and $\mathrm{H} 2030$ cells were irradiated at the indicated doses with a UV lamp (254 nm).

Cell viability assays. A549 and H2030 cells were cultured in 96-well plates at a density of $1-1.5 \times 10^{4}$ cells/well in $150 \mu \mathrm{l}$ of complete medium. Each group was repeated in six separate wells. MTT reagent $[15 \mu \mathrm{l}, 5 \mathrm{mg} / \mathrm{ml}$ in phosphate-buffered saline (PBS)] was added to each well for $4 \mathrm{~h}$. After $4 \mathrm{~h}$, each well was dissolved in $150 \mu \mathrm{l}$ DMSO. Absorbance was recorded at a wavelength of $490 \mathrm{~nm}$.

siRNA transfection. Prior to $12 \mathrm{~h}$ of transfection, $1 \times 10^{5}$ cells were cultured in 6-well plates in normal medium, with a target of $40-60 \%$ confluency at the time of transfection. Cells were transfected with $50 \mathrm{nmol} / \mathrm{l}$ of siRNA using Lipofectamine RNAiMAX (Invitrogen, Carlsbad, CA, USA) according to the manufacturer's protocol. Cells were harvested for western blotting at $48 \mathrm{~h}$ post-transfection.

Western blot analysis. Following treatment, A549 and H2030 cells were washed with cold PBS twice and then $200 \mu \mathrm{l}$ radioimmunoprecipitation (RIPA) buffer [50 mM Tris- $\mathrm{HCl}$ (pH 6.8), 0.1\% SDS, $150 \mathrm{mM} \mathrm{NaCl}, 1 \mathrm{mM}$ EDTA, $0.1 \mathrm{mM}$ $\mathrm{Na}_{3} \mathrm{VO}_{4}, 1 \mathrm{mM}$ sodium fluoride $(\mathrm{NaF}), 1 \%$ Triton $\mathrm{X}-100,1 \%$ NP-40, $1 \mathrm{mM}$ dithiothreitol, and 1mM PMSF, $1 \mu \mathrm{g} / \mathrm{ml}$ aprotinin, $1 \mu \mathrm{g} / \mathrm{ml}$ leupeptin, $1 \mu \mathrm{g} / \mathrm{ml}$ pepstatin $\mathrm{A}]$ was added to each dish. Cell lysates were shaken at $4{ }^{\circ} \mathrm{C}$ for $20 \mathrm{~min}$ and then centrifuged at $13,000 \mathrm{x} \mathrm{g}$ for $15 \mathrm{~min}$. Protein concentrations in the supernatants were detected using the BCA protein assay. For western blot analysis, $45 \mu \mathrm{g}$ protein were separated by $10 \%$ (w/v) SDS-polyacrylamide gel electrophoresis and transferred onto PVDF membranes and were then blocked with 5\% (w/v) skim milk in buffer [10 mM Tris- $\mathrm{HCl}(\mathrm{pH} 7.6), 100 \mathrm{mM}$ $\mathrm{NaCl}$, and $0.1 \%(\mathrm{v} / \mathrm{v})$ Tween-20] for $1 \mathrm{~h}$ at room temperature; the primary antibodies were added overnight at $4^{\circ} \mathrm{C}$. The following day, membranes were incubated with secondary antibodies (Thermo Scientific) for $1 \mathrm{~h}$ at room temperature. The semi-quantitation of proteins was surveyed with a Tanon GIS gel imager system.

Statistical analysis. The data were analyzed by t-test. $\mathrm{P}<0.05$ was considered to represent a statistically significant difference. Data are representative of three independent experiments performed in triplicate.

\section{Results}

UV decreases the cell viability of A549 and H2030. To examine the effect of UV on the cell viability of the lung cancer cell lines A549 and H2030, we used MTT to detect the change of cell viability of the A549 and H2030 cell lines. We treated A549 and H2030 cells with UV at different times and intensities. UV decreased cell viability significantly in A549 cells (Fig. 1A and B). The same phenomenon was observed in H2030 cells (Fig. 1C and D). These results revealed that UV decreased the cell viability of the lung cancer cell lines A549 and $\mathrm{H} 2030$.

UV induces apoptosis in A549 and H2030 cells. Based on the above results, we inquired whether the inhibition of A549 and H2030 growth by UV was due to apoptosis. We detected the apoptotic relative proteins caspase- 3 and PARP. UV increased the expression of cleaved caspase-3 and cleaved PARP in A549 and $\mathrm{H} 2030$ cells, which indicated that UV can induce apoptosis in the lung cancer cell lines (Fig. 2). Moreover, UV-induced apoptosis in A549 and H2030 cells was associated with the release of cytochrome $c$, indicating that it was mediated via the mitochondrial pathway (Fig. 2C and F). Thus, UV induced lung cancer cell apoptosis through the mitochondrial apoptotic pathway.

$U V$ enhances the expression of $C K 2 a$. It was reported that UV can activate CK2 in tumor cells (10). We detected the expression of CK2a in A549 and H2030 cells following UV treatment. UV also increased the expression of CK2a in the lung cancer cell lines (Fig. 3).

Inhibition of CK2 increases apoptosis in A549 and H2O3O cells induced by $U V$. Aside from inducing apoptosis, UV also increases the expression of CK2a. However, the effect of active CK2 on the growth inhibition of tumor cells by UV is unknown. Therefore, we next used the CK2 siRNA and CK2 inhibitor TBB to explore the relationship between the activation of CK2 and growth inhibition induced by UV. CK2 siRNA decreased the expression of CK2a (Fig. 4A and B). Inhibition of CK2 increased the growth inhibition in A549 and H2030 cells induced by UV (Fig 4C and D).

Subsequently, we detected the apoptotic relative proteins cytochrome $c$ and caspase-3. CK2 siRNA increased the expression of cytochrome $c$ and cleaved caspase-3 in A549 and H2030 cells induced by UV (Fig. 4E-H). 

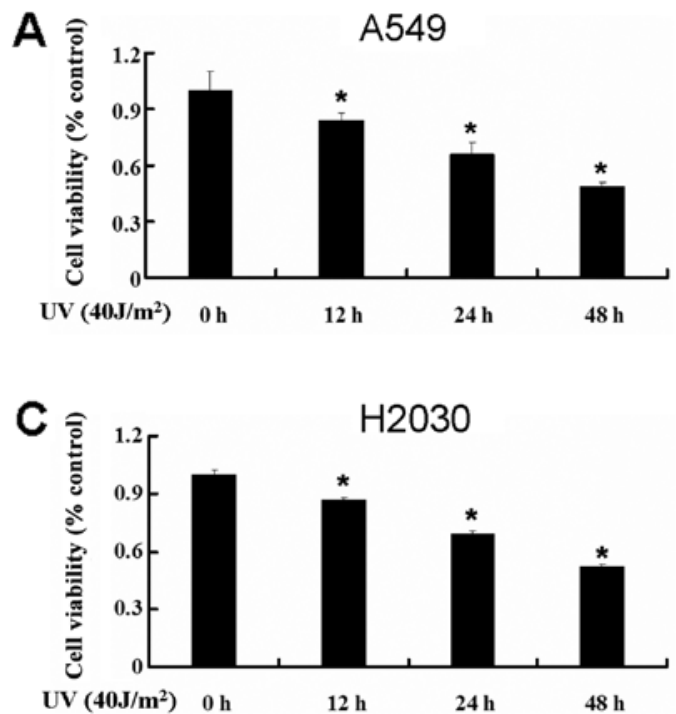
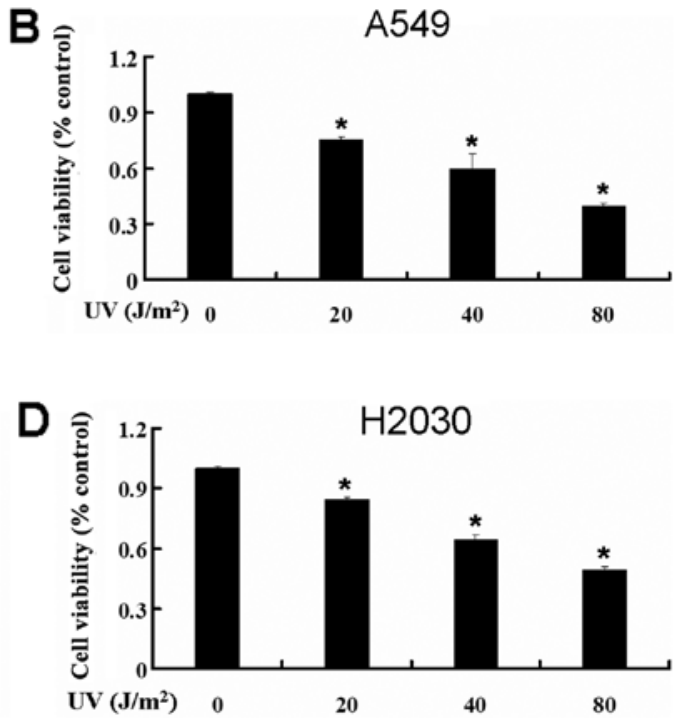

Figure 1. UV decreases the cell viability of the lung cancer cell lines A549 and H2030. (A) A549 cells were treated with $40 \mathrm{~J} / \mathrm{m}^{2} \mathrm{UV}$ for 12,24 and $48 \mathrm{~h}$. Cell viability was determined by MTT assay. Data are presented as the means \pm SD, n=6. (B) A549 cells were treated with 20,40 and $80 \mathrm{~J} / \mathrm{m}^{2} \mathrm{UV}$ for $24 \mathrm{~h}$. Cell viability was determined by MTT assay. (C) H2030 cells were treated with $40 \mathrm{~J} / \mathrm{m}^{2} \mathrm{UV}$ for 12,24 and $48 \mathrm{~h}$. Cell viability was determined by MTT assay. Data are presented as the means $\pm \mathrm{SD}, \mathrm{n}=6$. (D) $\mathrm{H} 2030$ cells were treated with 20,40 and $80 \mathrm{~J} / \mathrm{m}^{2} \mathrm{UV}$ for $24 \mathrm{~h}$. Cell viability was determined by MTT assay. Data are presented as the means $\pm \mathrm{SD}, \mathrm{n}=6$. $^{*} \mathrm{P}<0.05$ vs. control group.

A

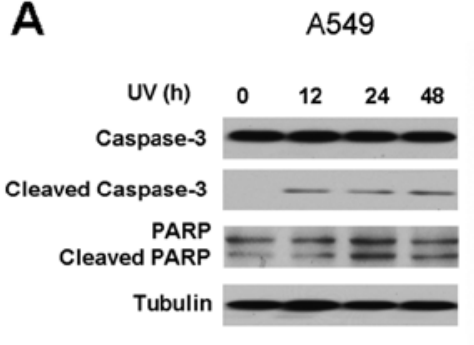

D

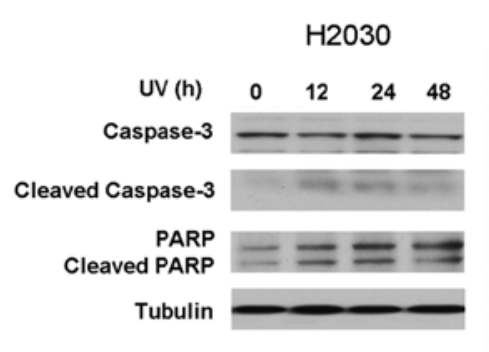

B

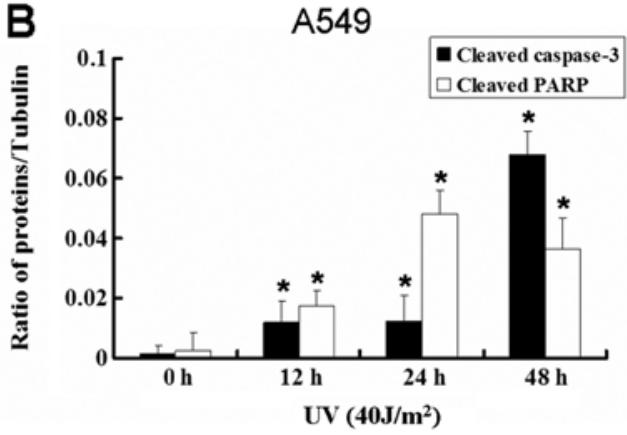

$\mathbf{E}$

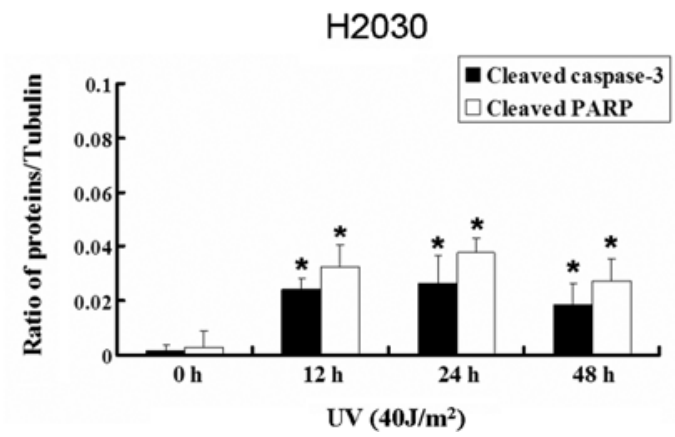

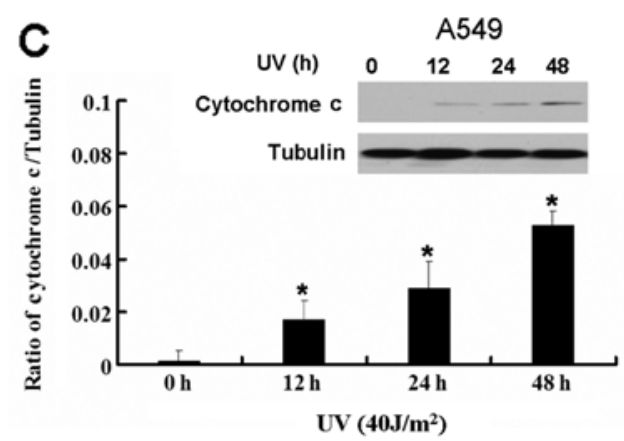

F

$\mathrm{H} 2030$

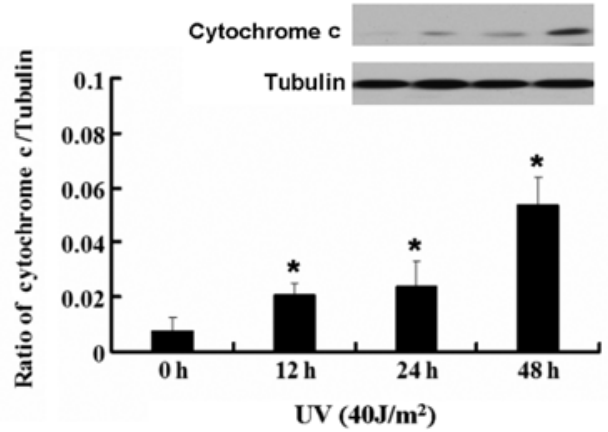

Figure 2. UV induces apoptosis in A549 and H2030 cells. (A) Western blot analysis for the expression of caspase-3, activated caspase-3 and cleaved PARP in A549 cells treated with $40 \mathrm{~J} / \mathrm{m}^{2} \mathrm{UV}$ for 12,24 and $48 \mathrm{~h}$. (B) Quantitation of activated caspase-3 and cleaved PARP protein levels. (C) Western blot analysis for the expression of cytochrome $c$ in A549 cells treated with $40 \mathrm{~J} / \mathrm{m}^{2} \mathrm{UV}$ for 12, 24 and $48 \mathrm{~h}$. (D) Western blot analysis for the expression of caspase-3, activated caspase-3 and cleaved PARP in H2030 cells treated with $40 \mathrm{~J} / \mathrm{m}^{2} \mathrm{UV}$ for 12, 24 and $48 \mathrm{~h}$. (E) Quantitation of activated caspase-3 and cleaved PARP protein levels. (F) Western blot analysis for the expression of cytochrome $c$ in $\mathrm{H} 2030$ cells treated with $40 \mathrm{~J} / \mathrm{m}^{2} \mathrm{UV}$ for 12, 24 and $48 \mathrm{~h}$. Data are presented as the means $\pm \mathrm{SD}, \mathrm{n}=3$. ${ }^{*} \mathrm{P}<0.05$ vs. control group.

We also used the CK2 inhibitor TBB to explore the role of CK2 in apoptosis in A549 and H2030 cells induced by UV. TBB also enhanced the growth inhibition induced by UV in A549 and H2030 cells (Fig. 5A and B). UV increased the expression of the apoptotic relative proteins caspase-3, PARP and cytochrome $c$ in A549 and H2030 cells (Fig. 5C-H). Thus, inhibition of CK2 increases the apoptosis induced by UV. 


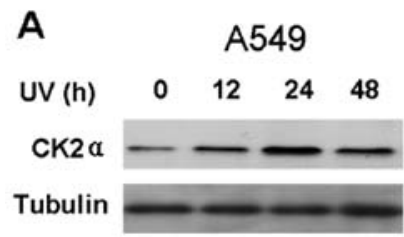

C

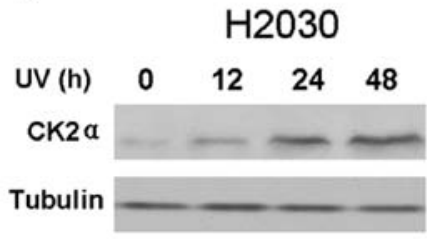

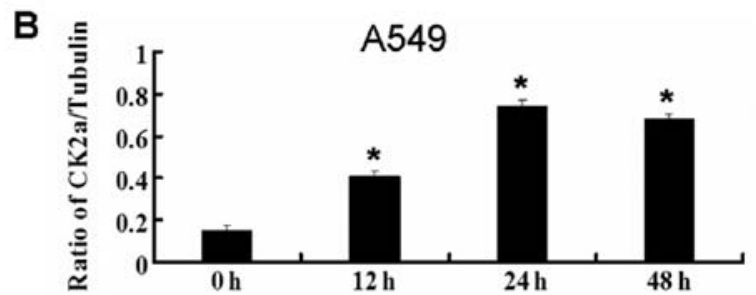

D

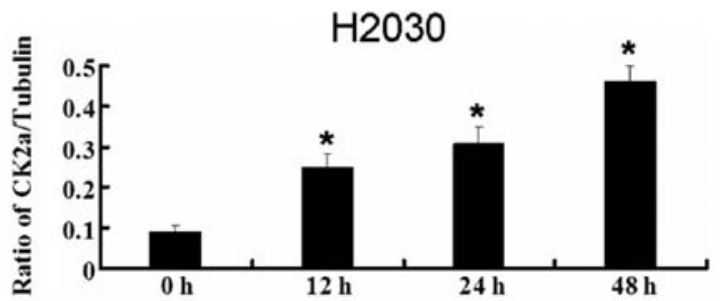

Figure 3. UV enhances the expression of CK2a. (A) Western blot analysis for the expression of CK2a in A549 cells treated with $40 \mathrm{~J} / \mathrm{m}^{2} \mathrm{UV}$ for 12,24 and $48 \mathrm{~h}$. (B) Quantitation of CK2a in A549 cells treated with $40 \mathrm{~J} / \mathrm{m}^{2} \mathrm{UV}$ for 12,24 and $48 \mathrm{~h}$. (C) Western blot analysis for the expression of CK2a in H2030 cells treated with $40 \mathrm{~J} / \mathrm{m}^{2} \mathrm{UV}$ for 12, 24 and $48 \mathrm{~h}$. (D) Quantitation of CK2a in H2030 cells treated with $40 \mathrm{~J} / \mathrm{m}^{2} \mathrm{UV}$ for 12,24 and $48 \mathrm{~h}$. Data are presented as the means $\pm \mathrm{SD}, \mathrm{n}=3$. ${ }^{*} \mathrm{P}<0.05$ vs. control group.
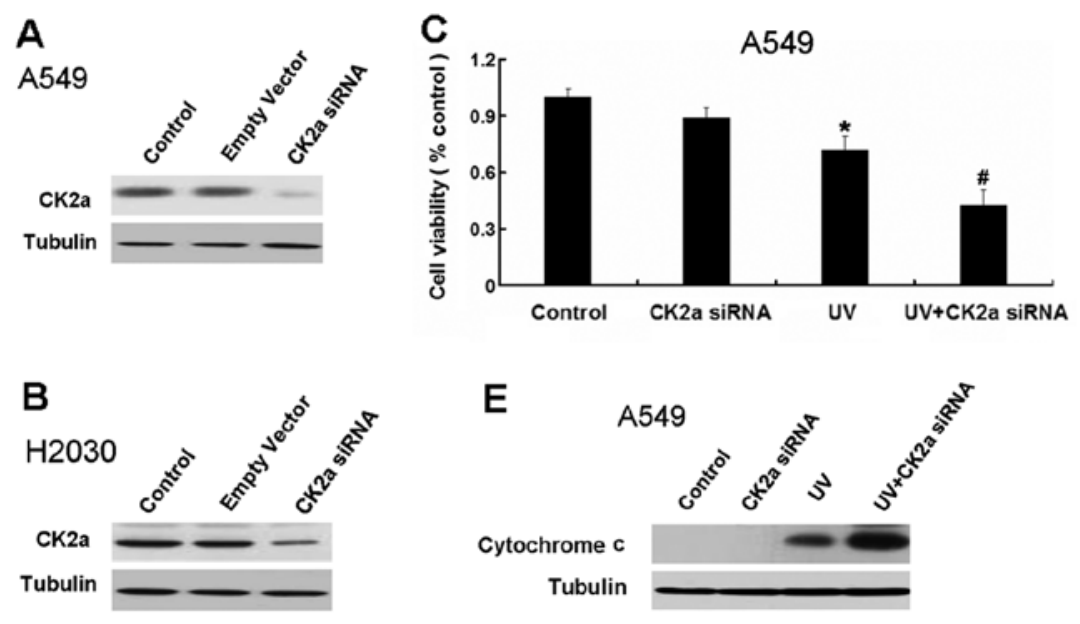

E

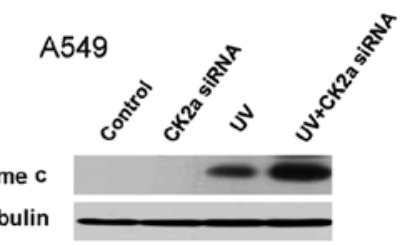

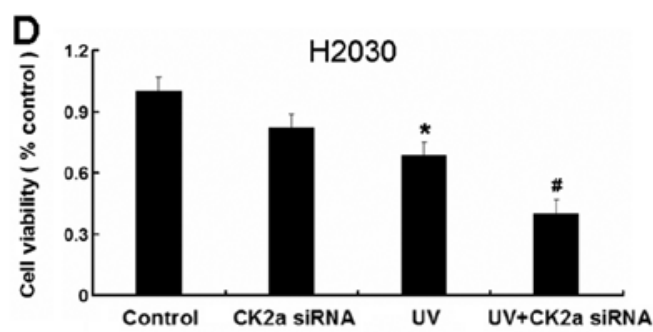

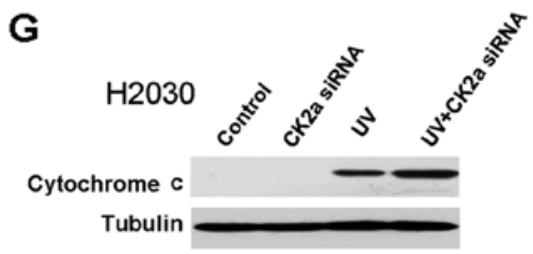

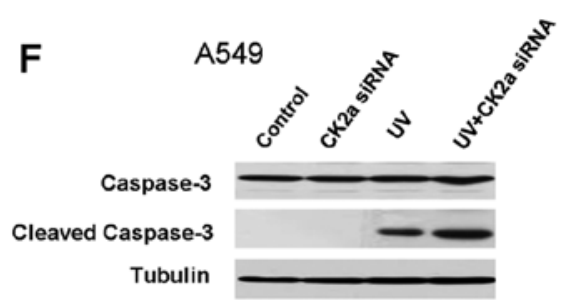

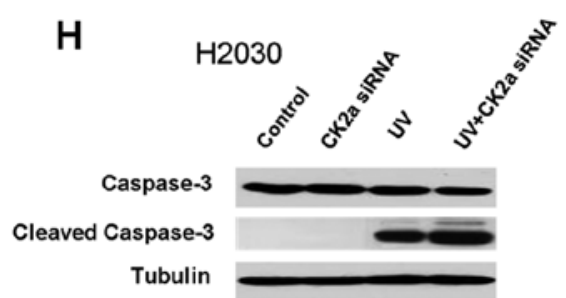

Figure 4. Inhibition of CK2 by CK2a siRNA increases apoptosis in A549 and H2030 cells induced by UV. (A) Western blot analysis for the expression of CK2a in A549 cells transfected with empty vector and CK2a siRNA for $24 \mathrm{~h}$. (B) Western blot analysis for the expression of CK2a in H2030 cells transfected with empty vector and CK2a siRNA for $24 \mathrm{~h}$. (C) A549 cells were treated with CK2a siRNA, UV and a combination of CK2a siRNA and UV for $24 \mathrm{~h}$. Cell viability was determined by MTT assay. Data are presented as the means \pm SD, $n=6$. (D) H2030 cells were treated with CK2a siRNA, UV and a combination of CK2a siRNA and UV for $24 \mathrm{~h}$. Cell viability was determined by MTT assay. Data are presented as the means \pm SD, $n=6$. (E) Western blot analysis for the expression of cytochrome $c$ in A549 cells treated with CK2a siRNA, UV and a combination of CK2a siRNA and UV for $24 \mathrm{~h}$. (F) Western blot analysis for the expression of caspase-3, activated caspase-3 in A549 cells treated with CK2a siRNA, UV and a combination of CK2a siRNA and UV for $24 \mathrm{~h}$. (G) Western blot analysis for the expression of cytochrome $c$ in H2030 cells treated with CK2a siRNA, UV and a combination of CK2a siRNA and UV for 24 h. (H) Western blot analysis for the expression of caspase-3, activated caspase-3 in H2030 cells treated with CK2a siRNA, UV and a combination of CK2a siRNA and UV for $24 \mathrm{~h}$. All UV treatment mentioned in this figure is $40 \mathrm{~J} / \mathrm{m}^{2}$. Data are presented as the means $\pm \mathrm{SD}, \mathrm{n}=3$. ${ }^{*} \mathrm{P}<0.05$ vs. control group; ${ }^{~} \mathrm{P}<0.05$ vs. $\mathrm{UV}$ group.

The action of $C K 2$ in the $U V$-induced apoptosis may be through the recovery of the PML expression in A549 and H2030 cells. It is reported that active CK2 can promote the degradation of PML which is a tumor suppressor (2). As seen above, UV activates CK2 in lung cancer cell lines. Thus, we further detected the expression PML following UV treatment. UV decreased the expression of PML in A549 and H2030 cells (Fig. 6). Based on these results, UV may decrease the expression of PML through the activation of CK2. We next detected the effect of CK2 on the expression of PML in A549 
A

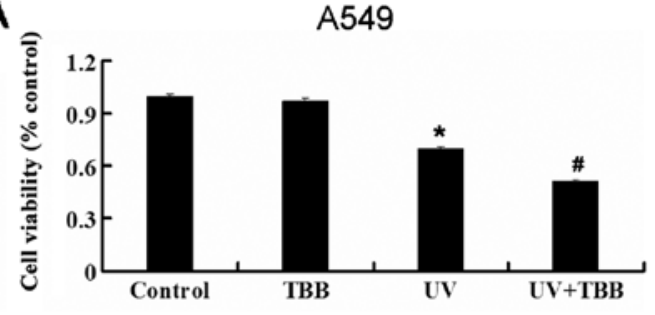

B

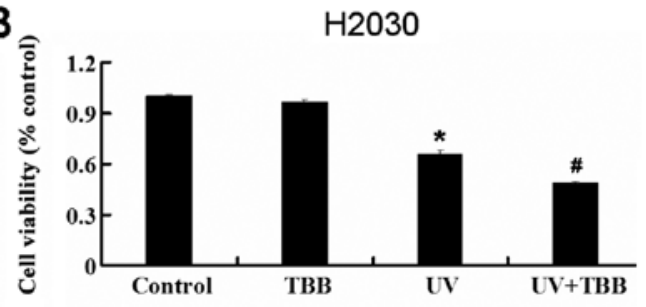

C

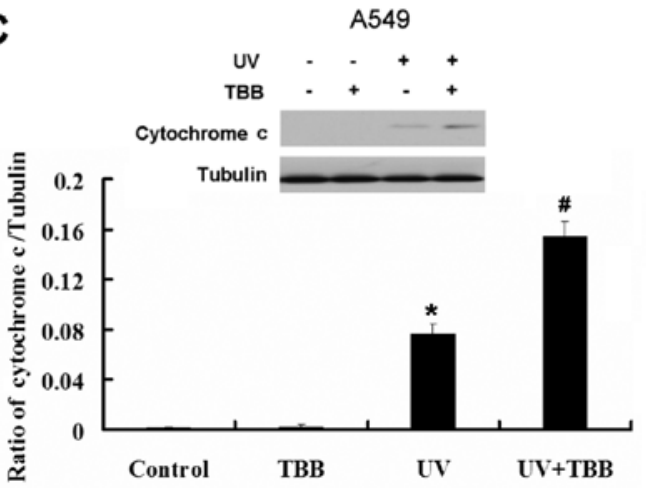

D
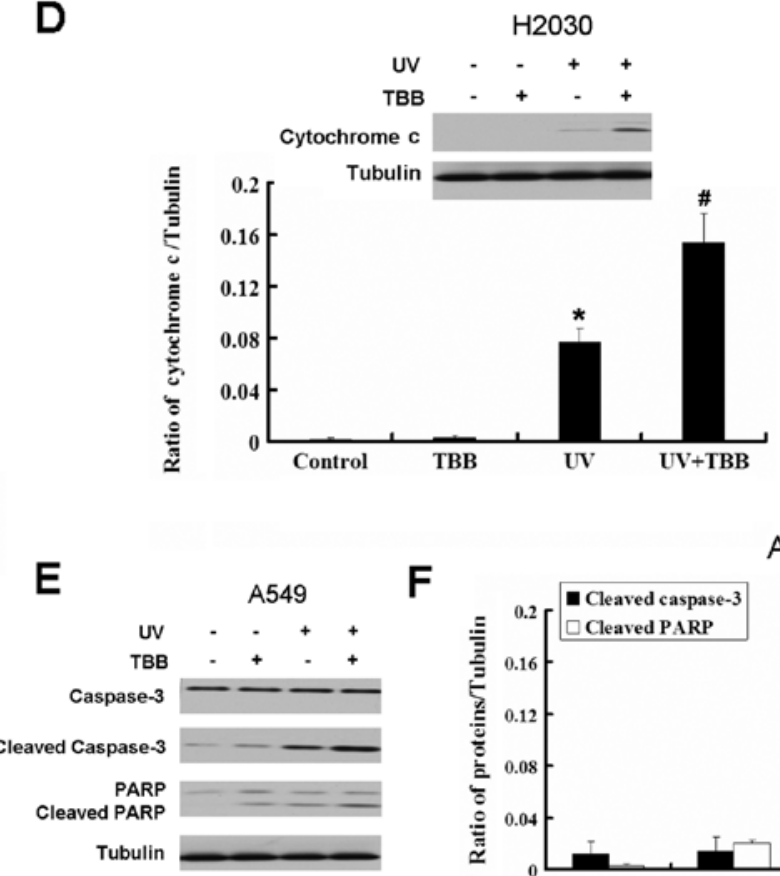

F

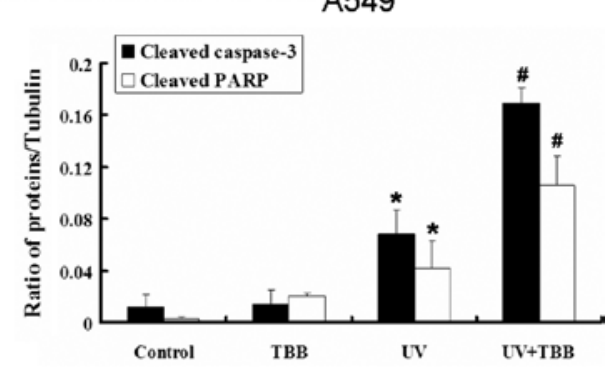

$\mathrm{H}$
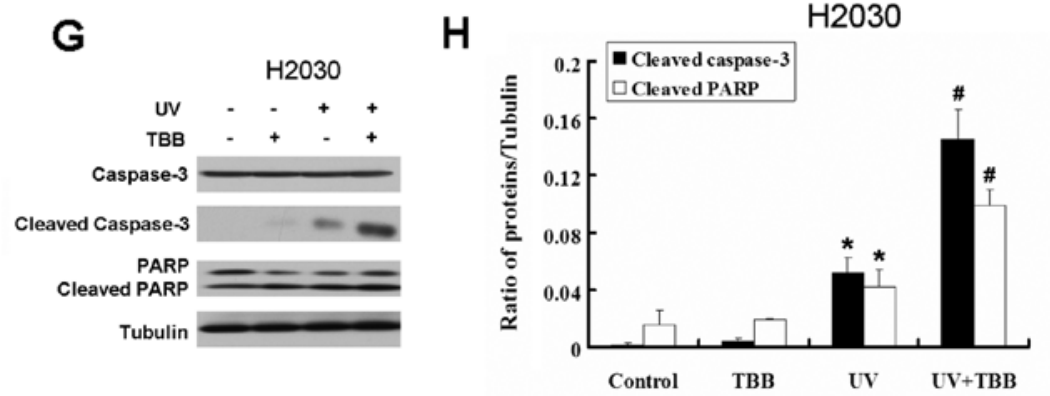

Figure 5. CK2 inhibitor TBB increases apoptosis in A549 and H2030 cells induced by UV. (A) A549 cells were treated with TBB (20 $\mu \mathrm{M}, 30 \mathrm{~min}$ pretreatment), UV and a combination of TBB and UV for $24 \mathrm{~h}$. Cell viability was determined by MTT assay. Data are presented as the means \pm SD, n=6. (B) H2030 cells were treated with TBB $(20 \mu \mathrm{M}, 30$ min pretreatment), UV and a combination of TBB and UV for $24 \mathrm{~h}$. Cell viability was determined by MTT assay. Data are presented as the means $\pm \mathrm{SD}, \mathrm{n}=6$. (C) Western blot analysis for the expression of cytochrome $c$ in A549 cells treated with TBB $(20 \mu \mathrm{M}, 30$ min pretreatment), $\mathrm{UV}$ and a combination of TBB and UV for $24 \mathrm{~h}$. (D) Western blot analysis for the expression of cytochrome $c$ in $\mathrm{H} 2030$ cells treated with TBB (20 $\mu \mathrm{M}, 30$ min pretreatment), UV and a combination of TBB and UV for $24 \mathrm{~h}$. (E) Western blot analysis for the expression of caspase-3, activated caspase-3 and cleaved PARP in A549 cells treated with TBB $(20 \mu \mathrm{M}, 30$ min pretreatment), UV and a combination of TBB and UV for $24 \mathrm{~h}$. (F) Quantitation of activated caspase-3 and cleaved PARP protein levels. (G) Western blot analysis for the expression of caspase-3, activated caspase-3 and cleaved PARP in H2030 cells treated with TBB (20 $\mu \mathrm{M}, 30$ min pretreatment), UV and a combination of TBB and UV for $24 \mathrm{~h}$. (H) Quantitation of activated caspase-3 and cleaved PARP protein levels. All $\mathrm{UV}$ treatment mentioned in this figure is $40 \mathrm{~J} / \mathrm{m}^{2}$. Data are presented as the means $\pm \mathrm{SD}, \mathrm{n}=3,{ }^{*} \mathrm{P}<0.05$ vs. control group. ${ }^{\#} \mathrm{P}<0.05$ vs. $\mathrm{UV}$ group.

and $\mathrm{H} 2030$ cells treated by UV. CK2 siRNA and TBB recover the decrease of PML induced by UV (Fig. 7).

UV decreases the expression of PML through activation of CK2. Inhibition of CK2 by CK2 siRNA and TBB can recover the decrease of PML induced by UV. Therefore, the combination of UV and CK2 inhibitor may be an efficient strategy for the treatment of lung cancer.

\section{Discussion}

It is well known that high intensity UV radiation can lead to skin cancer, while proper intensity of UV radiation has been used to induce cell apoptosis in cancer therapy and basic experiment research (25-28). Aside from inducing apoptosis, it is reported that UV can activate the protein kinase CK2 (10). CK2, a Ser/Thr protein kinase, is associated with various types of human cancer, including lung cancer. In this study, we gained insight into the role of $\mathrm{CK} 2$ inhibition in cancer cell apoptosis induced by UV.

We first observed the effect of different irradiation times (from 0 to $48 \mathrm{~h}$ ) and different exposure doses of UV radiation (from 0 to $80 \mathrm{~J} / \mathrm{m}^{2}$ ) on two human lung cancer cell lines, A549 and $\mathrm{H} 2030$, via MTT assay. We found that the cells treated by UV radiation displayed lower cell growth ability in a time- and dose-dependent manner, compared with the non-treated group.

Apoptosis frequently involves the activation of caspase-3, accompanied by cleavage of substrates such as PARP and the release of cytochrome $c$ from mitochondria. Therefore, 
A

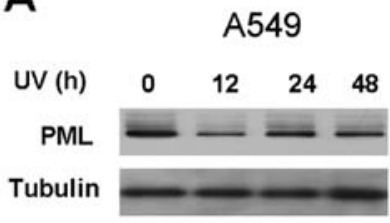

C

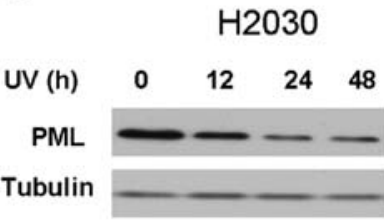

B

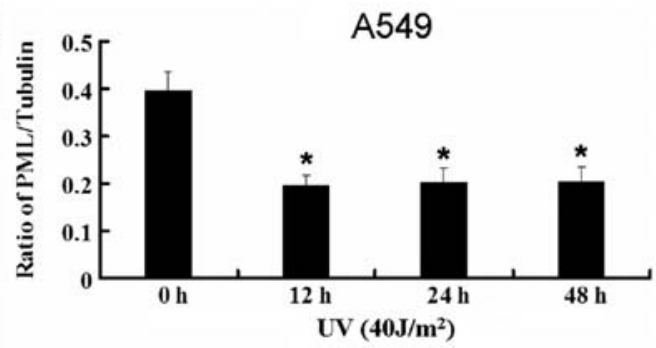

D

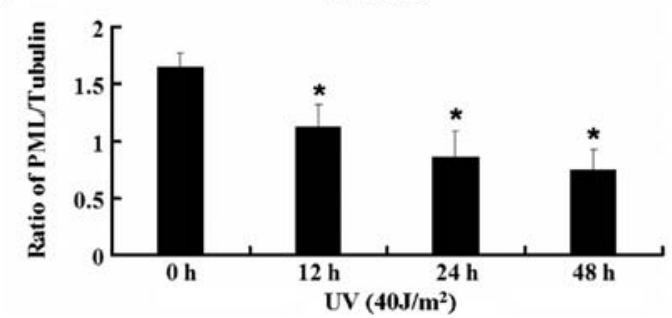

Figure 6. UV decreases the expression of PML. (A) Western blot analysis for the expression of PML in A549 cells treated with $40 \mathrm{~J} / \mathrm{m}^{2} \mathrm{UV}$ for 12,24 and 48 h. (B) Quantitation of PML in A549 cells treated with $40 \mathrm{~J} / \mathrm{m}^{2} \mathrm{UV}$ for 12,24 and $48 \mathrm{~h}$. (C) Western blot analysis for the expression of PML in H2030 cells treated with $40 \mathrm{~J} / \mathrm{m}^{2} \mathrm{UV}$ for 12, 24 and $48 \mathrm{~h}$. (D) Quantitation of PML in H2030 cells treated with $40 \mathrm{~J} / \mathrm{m}^{2} \mathrm{UV}$ for 12,24 and $48 \mathrm{~h}$. Data are presented as the means $\pm \mathrm{SD}, \mathrm{n}=3$. ${ }^{*} \mathrm{P}<0.05$ vs. control group.

A

A549

PML

Tubulin
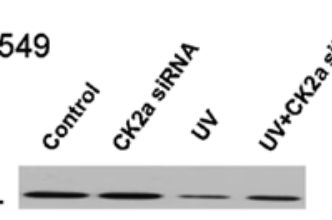

C

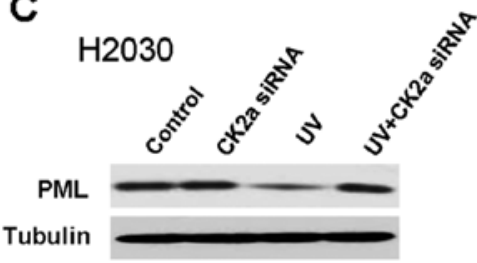

E

$\mathrm{H} 2030$

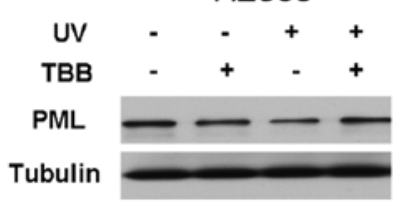

B

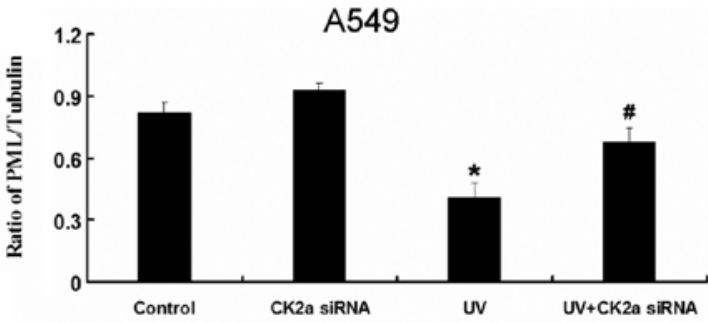

D

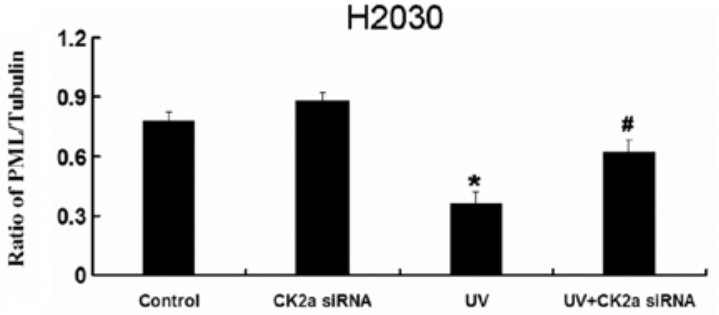

$\mathbf{F}$

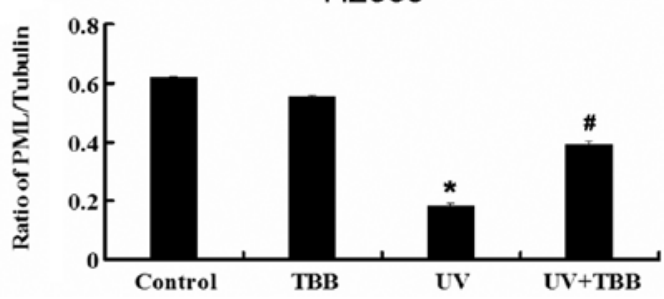

Figure 7. Inhibition of CK2 recovers the PML expression decrease in A549 and H2030 cells induced by UV. (A) Western blot analysis for the expression of PML in A549 cells treated with CK2a siRNA, UV and a combination of CK2a siRNA and UV for 24 h. (B) Quantitation of PML in A549 cells treated with CK2a siRNA, UV and a combination of CK2a siRNA and UV for $24 \mathrm{~h}$. (C) Western blot analysis for the expression of PML in H2030 cells treated with CK2a siRNA, UV and a combination of CK2a siRNA and UV for $24 \mathrm{~h}$. (D) Quantitation of PML in H2030 cells treated with CK2a siRNA, UV and a combination of CK2a siRNA and UV for $24 \mathrm{~h}$. (E) Western blot analysis for the expression of PML in H2030 cells treated with TBB (20 $\mu$ M, 30 min pretreatment), UV and a combination of TBB and UV for $24 \mathrm{~h}$. (F) Quantitation of the expression of PML in H2030 cells treated with TBB (20 $\mu \mathrm{M}, 30 \mathrm{~min}$ pretreatment), UV and a combination of TBB and UV for $24 \mathrm{~h}$ activated caspase-3 and cleaved PARP protein levels. All UV treatment mentioned in this figure is $40 \mathrm{~J} / \mathrm{m}^{2}$. Data are presented as the means $\pm \mathrm{SD}, \mathrm{n}=3 .{ }^{*} \mathrm{P}<0.05$ vs. control group. ${ }^{\#} \mathrm{P}<0.05$ vs. UV group.

we investigated the cell apoptosis treated by UV by detecting these apoptotic protein marker expressions by western blotting. The results showed that the cleavage of caspase-3 PARP expressions and cytochrome $c$ release levels were upregulated respectively following UV treatment in a time-dependent manner. In the subsequent experiment, we chose the UV 
radiation intensity of $40 \mathrm{~J} / \mathrm{m}^{2}$ and in conjunction with the CK2 inhibitor TBB, to analyze the combination effect on cancer cell apoptosis.

These results showed that UV can induce apoptosis at the same time as activating CK2 in lung cancer cell lines. However, the role of CK2 in apoptosis induced by UV is unknown. We used CK2 siRNA and CK2 inhibitor to inhibit CK2 activation in lung cancer cell lines. Compared with the single-treatment group (UV radiation group), the MTT assay showed that the combination of UV and CK2a siRNA displayed the lowest viability. To further clarify the molecular events underlying apoptosis, alterations of several executive components in apoptotic machinery were examined. One of them is cytochrome $c$ release. The results showed that cytochrome $c$ release was increased heavily in the combination treatment group compared with that in each single-treatment group and the non-treated group. Consistent with these results, the cleaved caspase-3 also increased markedly in the co-treatment group compared with that in other groups.

The observation that TBB, a very selective cell-permeant inhibitor of protein kinase CK2 (29), displays a striking selectivity for this enzyme only amid a panel of more than 30 protein kinases, provided a new tool for investigating the biological functions of this pleiotropic and, in some respects, still enigmatic kinase. In this study, we further used the CK2 inhibitor TBB to explore the role of CK2 in apoptosis induced by UV. Similar to CK2 siRNA, the CK2 inhibitor TBB also enhanced the growth inhibition by UV in the lung cancer cell lines A549 and H2030. Moreover, the combination of UV and TBB increased the apoptotic relative proteins caspase-3, PARP and cytochrome $c$ in A549 and H2030 cells

A previous study defined the negative relationship between CK2 and PML, a tumor suppressor protein which is capable of inducing growth and apoptosis (30). When CK2 kinase activity is upregulated (as often happens in human cancer), PML is polyubiquitinylated and degraded (31). Scaglioni et al (15) demonstrated that CK2, a kinase associated with cancer promotion, phosphorylates PML and targets it for degradation by the proteasome. Loss of the critical CK2 phosphorylation site in PML results in stabilization of this protein, enhancement of PML-induced apoptosis and senescence, and abrogation of sensitivity to CK2 inhibitors. In conditions of oncogenic stress, such as the ones triggered by oncogenic Ras, PML is activated and exerts its tumor suppressive function. PML has been the focus of extensive investigations due to its multiple tumor-suppressive functions and its ability to regulate key tumor-suppressive pathways $(32,33)$. PML degradation upon CK2 activation could account for the frequent loss of PML expression observed in multiple human tumors (2). Our results showed that the tumor suppressor protein PML expression was decreased in the UV group, while use of CK2a siRNA or TBB significantly recovered the expression of PML.

Collectively, our results revealed that the alterations of diverse apoptotic factors, including cytochrome $c$, caspase-3 and PARP, may contribute to the enhancement of apoptosis in human lung cancer cells via combination treatment of CK2a siRNA or TBB with UV radiation. The recovered PML expression by CK2 inhibitor TBB is part of a cellular circuitry that enhances apoptosis. Further studies including generating a lung cancer cell xenograft mouse model should be conducted to confirm our results. We therefore propose that therapy with specific CK2 inhibitors, such as TBB, combined with radiation or other DNA-damaging agents may generate effective results as an anticancer therapy tool.

\section{References}

1. Greenlee RT, Hill-Harmon MB, Murray T and Thun M: Cancer statistics, 2001. CA Cancer J Clin 51: 15-36, 2001.

2. Riley PA: Free radicals in biology: oxidative stress and the effects of ionizing radiation. Int J Radiat Biol 65: 27-33, 1994.

3. Lentine B, Antonucci L, Hunce R, Edwards J, Marallano V and Krucher NA: Dephosphorylation of threonine-821 of the retinoblastoma tumor suppressor protein $(\mathrm{Rb})$ is required for apoptosis induced by UV and Cdk inhibition. Cell Cycle 11: 3324-3330, 2012.

4. Choi YJ, Kim YJ, Lee JW, Lee Y, Lim YB and Chung HW: Cyto-/genotoxic effect of $\mathrm{CdSe} / \mathrm{ZnS}$ quantum dots in human lung adenocarcinoma cells for potential photodynamic UV therapy applications. J Nanosci Nanotechnol 12: 2160-2168, 2012.

5. Huang J, Zhang L, Liu W, et al: CCDC134 interacts with hADA2a and functions as a regulator of hADA2a in acetyltransferase activity, DNA damage-induced apoptosis and cell cycle arrest. Histochem Cell Biol 138: 41-55, 2012.

6. Cao C, Lu S, Kivlin R, et al: AMP-activated protein kinase contributes to UV- and $\mathrm{H}_{2} \mathrm{O}_{2}$-induced apoptosis in human skin keratinocytes. J Biol Chem 283: 28897-28908, 2008.

7. Kyriakis JM and Avruch J: Protein kinase cascades activated by stress and inflammatory cytokines. Bioessays 18: 567-577, 1996.

8. Johnson GL and Lapadat R: Mitogen-activated protein kinase pathways mediated by ERK, JNK, and p38 protein kinases. Science 298: 1911-1912, 2002.

9. Seo M, Cho CH, Lee YI, et al: Cdc42-dependent mediation of UV-induced p38 activation by $\mathrm{G}$ protein betagamma subunits. J Biol Chem 279: 17366-17375, 2004.

10. Kato T Jr, Delhase M, Hoffmann A and Karin M: CK2 is a C-terminal IkappaB kinase responsible for NF-kappaB activation during the UV response. Mol Cell 12: 829-839, 2003.

11. Roux PP and Blenis J: ERK and p38 MAPK-activated protein kinases: a family of protein kinases with diverse biological functions. Microbiol Mol Biol Rev 68: 320-344, 2004.

12. Keller DM, Zeng X, Wang Y, et al: A DNA damage-induced p53 serine 392 kinase complex contains CK2, hSpt16, and SSRP1. Mol Cell 7: 283-292, 2001.

13. Jacks KA and Koch CA: Differential regulation of mitogen- and stress-activated protein kinase-1 and -2 (MSK1 and MSK2) by CK2 following UV radiation. J Biol Chem 285: 1661-1670, 2010.

14. Sayed M, Kim SO, Salh BS, Issinger OG and Pelech SL: Stressinduced activation of protein kinase CK2 by direct interaction with p38 mitogen-activated protein kinase. J Biol Chem 275: 16569-16573, 2000.

15. Scaglioni PP, Yung TM, Cai LF, et al: A CK2-dependent mechanism for degradation of the PML tumor suppressor. Cell 126: 269-283, 2006.

16. Landesman-Bollag E, Song DH, Romieu-Mourez R, et al: Protein kinase CK2: signaling and tumorigenesis in the mammary gland. Mol Cell Biochem 227: 153-165, 2001.

17. Giroux V, Dagorn JC and Iovanna JL: A review of kinases implicated in pancreatic cancer. Pancreatology 9: 738-754, 2009.

18. Ruzzene $M$ and Pinna LA: Addiction to protein kinase CK2: a common denominator of diverse cancer cells? Biochim Biophys Acta 1804: 499-504, 2010.

19. Trembley JH, Wang G, Unger G, Slaton J and Ahmed K: Protein kinase CK2 in health and disease: CK2: a key player in cancer biology. Cell Mol Life Sci 66: 1858-1867, 2009.

20. Ahmed K, Davis AT, Wang H, et al: Significance of protein kinase CK2 nuclear signaling in neoplasia. J Cell Biochem (Suppl) 35: 130-135, 2000.

21. Piazza F, Manni S, Ruzzene M, et al: Protein kinase CK2 in hematologic malignancies: reliance on a pivotal cell survival regulator by oncogenic signaling pathways. Leukemia 26: 1174-1179, 2012.

22. Pinna LA: Protein kinase CK2: a challenge to canons. J Cell Sci: 115: 3873-3878, 2002.

23. Ahmed K, Gerber DA and Cochet C: Joining the cell survival squad: an emerging role for protein kinase CK2. Trends Cell Biol 12: 226-230, 2002 . 
24. Manni S, Brancalion A, Tubi LQ, et al: Protein kinase CK2 protects multiple myeloma cells from ER stress-induced apoptosis and from the cytotoxic effect of HSP90 inhibition through regulation of the unfolded protein response. Clin Cancer Res 18: 1888-1900, 2012.

25. Pustisek N and Situm M: UV-radiation, apoptosis and skin. Coll Antropol 35 (Suppl 2): 339-341, 2011.

26. Zandi S, Kalia S and Lui H: UVA1 phototherapy: a concise and practical review. Skin Therapy Lett 17: 1-4, 2012.

27. Tomas D: Apoptosis, UV-radiation, precancerosis and skin tumors. Acta Med Croatica 63 (Suppl 2): 53-58, 2009 (In Croatian).

28. Lee WR, Shen SC, Lin HY, et al: Wogonin and fisetin induce apoptosis in human promyeloleukemic cells, accompanied by a decrease of reactive oxygen species, and activation of caspase 3 and $\mathrm{Ca}(2+)$-dependent endonuclease. Biochem Pharmacol 63 . 225-236, 2002
29. Sarno S, Reddy H, Meggio F, et al: Selectivity of 4,5,6,7-tetrabromobenzotriazole, an ATP site-directed inhibitor of protein kinase CK2 ('casein kinase-2'). FEBS Lett 496: 44-48, 2001.

30. Bernardi R and Pandolfi PP: Structure, dynamics and functions of promyelocytic leukaemia nuclear bodies. Nat Rev Mol Cell Biol 8: 1006-1016, 2007.

31. Scaglioni PP, Yung TM, Choi S, Baldini C, et al: CK2 mediates phosphorylation and ubiquitin-mediated degradation of the PML tumor suppressor. Mol Cell Biochem 316: 149-154, 2008.

32. de Stanchina E, Querido E, Narita M, et al: PML is a direct p53 target that modulates p53 effector functions. Mol Cell 13: 523-535, 2004

33. Lavau C, Marchio A, Fagioli M, et al: The acute promyelocytic leukaemia-associated PML gene is induced by interferon. Oncogene 11: 871-876, 1995. 